\title{
REFORMA LABORAL Y CONSTITUCIONALISMO SOCIAL EN REPÚBLICA DOMINICANA. EL EFECTO TRANSFORMADOR DE LAS RELACIONES LABORALES A TRAVÉS DEL CONTROL CONCENTRADO DE CONSTITUCIONALIDAD*
}

\author{
LABOR REFORM AND SOCIAL CONSTITUTIONALISM \\ IN THE DOMINICAN REPUBLIC. \\ THE TRANSFORMING EFFECT OF LABOR RELATIONS \\ THROUGH CONCENTRATED CONTROL \\ OF CONSTITUTIONALITY
}

\section{RÉFORME DU TRAVAIL ET CONSTITUTIONNALISME SOCIAL EN RÉPUBLIQUE DOMINICAINE. L'EFFET TRANSFORMATEUR DES RELATIONS DE TRAVAIL GRÂCE À UN CONTRÔLE CONCENTRÉ DE LA CONSTITUTIONNALITÉ}

$$
\text { Ramón Jorge TAVERAs* }
$$

\begin{abstract}
RESUMEN: En este artículo se analiza el impacto que las decisiones del TC han tenido en la reforma laboral en la República Dominicana. Muchos de los países latinoamericanos han puesto en funcionamiento tribunales o cortes constitucionales para garantizar e interpretar los derechos fundamentales. Las decisiones del Tribunal Constitucional establecen precedentes vinculantes para todos los poderes del Estado.
\end{abstract}

\footnotetext{
* Recibido el 17 de noviembre de 2020 y aceptado para su publicación el 15 de marzo de 2021.

** Licenciado en derecho Magna Cum Laude. Master en derecho constitucional y libertades Fundamentales, por la Universidad Pantheon Sorbonne París. Licenciatura en Ciencias Navales, mención tecnólogo. Maestría en derecho marítimo por la Universidad Acción Pro Educación. Docente de la Academia Naval de la Armada de República Dominicana. Actualmente se desempeña como investigador asociado del Observatorio Judicial Dominicano.
} 
Dado que el constitucionalismo en los países de América Latina tiene un marcado matiz social, casi todas las constituciones de estos Estados han incluido en sus contenidos el derecho fundamental laboral, lo que hace importante la interpretación que estos tribunales realizan de los derechos laborales y los precedentes que se crean, en un contexto comparado.

El principal objetivo de este artículo es indagar en qué medida la participación del Tribunal Constitucional dominicano, en el ejercicio del control concentrado de constitucionalidad, ha contribuido, garantizar el derecho fundamental al trabajo durante su primer cuatrienio de actividad jurisdiccional (2012-2015), contribuyendo al desarrollo del constitucionalismo social dominicano a través de un efecto transformador de las relaciones laborales. En el Estado social dominicano, la actividad jurisprudencial de su Tribunal Constitucional puede contribuir a la construcción de indicadores, con el fin de determinar el estado actual en el que se encuentra este constitucionalismo social, actualmente, con énfasis en la garantía del derecho fundamental al trabajo, considerando que el constitucionalismo social promueve la creación, reinterpretación y la reforma laboral pasiva en la República Dominicana.

Palabras clave: derecho fundamental al trabajo, constitucionalismo social, reforma laboral, Tribunal Constitucional, control concentrado de constitucionalidad.

ABSTRACT: This article analyzes the impact that Constitutional Court decisions have had on the labor reform in the Dominican Republic. Many of the Latin American countries have established constitutional courts or tribunals to guarantee and interpret fundamental rights. The decisions of the constitutional court establish binding precedents for all powers of the State. Given that constitutionalism in Latin American countries has a marked social nuance, almost all the constitutions of these States have included in their contents, the fundamental labor law, which makes the interpretation that these courts make of labor rights and labor rights important. precedents that are created, in a comparative context.

The main objective of this article is to investigate to what extent the participation of the Dominican Constitutional Court in the exercise of concentrated control of constitutionality has contributed to guaranteeing the fundamental right to work during its first five years of judicial activity (2012-2015), contributing to the development of 
Dominican social constitutionalism through a transforming effect of labor relations. In the Dominican social state, the jurisprudential activity of its Constitutional Court can contribute to the construction of indicators, in order to determine the current state in which this social constitutionalism is currently; with emphasis on the guarantee of the fundamental right to work, considering that social constitutionalism promotes the creation, reinterpretation and passive labor reform in the Dominican Republic.

Keywords: fundamental right to work, social constitutionalism, labour reform, Constitutional Court, concentrated control of constitutionality.

RÉSUMÉ: Cet article analyse l'impact des décisions de la Cour constitutionnelle sur la réforme du travail en République dominicaine. De nombreux pays d'Amérique latine ont créé des cours ou des tribunaux constitutionnels pour garantir et interpréter les droits fondamentaux. Les décisions de la Cour constitutionnelle établissent des précédents contraignants pour tous les pouvoirs de l'État. Étant donné que le constitutionnalisme dans les pays d'Amérique latine a une nuance sociale marquée, presque toutes les constitutions de ces États ont inclus dans leur contenu, le droit du travail fondamental, ce qui rend importante l'interprétation que ces tribunaux font des droits du travail et des droits du travail précédents créés, dans un contexte comparatif.

L'objectif principal de cet article est d'étudier dans quelle mesuré la participation de la Cour constitutionnelle dominicaine à l'exercice du contrôle concentré de la constitutionnalité, a contribué à garantir le droit fondamental au travail pendant ses cinq premières années d'activité judiciaire (2012-2015), contribuant au développement du constitutionnalisme social dominicain à travers un effet transformateur des relations de travail. Dans l'État social dominicain, l'activité jurisprudentielle de sa Cour constitutionnelle peut contribuer à la construction d'indicateurs, afin de déterminer l'état actuel dans lequel se trouve actuellement ce constitutionnalisme social; en mettant lraccent sur la garantie du droit fondamental au travail, considérant que le constitutionnalisme social favorise la création, la réinterprétation et la réforme passive du travail en République dominicaine.

Mots-clés: droit fondamental au travail, constitutionnalisme social, réforme du travail, Cour constitutionnelle, contrôle concentré de la constitutionnalité. 
SUMARIO: I. Introducción. II. Constitucionalismo social latinoamericano y dominicano. III. Constitucionalización del derecho humano al trabajo en República Dominicana. IV. Control de constitucionalidad en el Estado social y democrático de derecho dominicano. V. Actividad jurisdiccional del Tribunal Constitucional en materia laboral durante 2012. VI. Actividad jurisdiccional del Tribunal Constitucional en materia laboral durante 2013. VII. Actividad jurisdiccional del Tribunal Constitucional en materia laboral durante 2014. VIII. Actividad jurisdiccional del Tribunal Constitucional en materia laboral durante 2015. IX. Efecto transformador de las relaciones laborales y reforma laboral. X. Reflexiones finales. XI. Bibliografía.

\section{INTRODUCCIÓN}

$\square$ n la República Dominicana, con la reforma constitucional del 26 de enero de 2010 se produjeron dos paradigmas importantes en torno al desarrollo del constitucionalismo social: 1) la concepción del Estado social y democrático de derecho y 2) la creación del Tribunal Constitucional (TC) dominicano para la defensa de la Constitución y garantía de los derechos fundamentales.

La puesta en funcionamiento de un órgano jurisdiccional especializado en materia constitucional tuvo connotaciones transcendentales en la transición de un Estado de derecho a un Estado constitucional garantista de los derechos humanos. En efecto, la constitucionalización de las diversas ramas del derecho y del sistema de justicia, es corolario de la administración de justicia constitucional y protección de los derechos fundamentales consagrados en la carta magna.

Dentro del catálogo de los derechos fundamentales que consagra la carta sustantiva de República Dominicana, se destaca el derecho fundamental al trabajo debido a las peculiaridades que presenta. En sentido lato, el derecho fundamental al trabajo, respecto a la división clásica de las ramas del derecho, constituye una especie de tercer género entre lo público y lo privado: un derecho social. Por lo que la creación de una jurisdicción especializada para la protección de los derechos fundamentales nos inquieta a indagar sobre la tendencia y perspectiva que ha tenido el derecho fundamental al trabajo tanto a priori como a posteriori del establecimiento de una jurisdicción especializada en materia constitucional.

Lo anterior, con el objetivo principal de inquirir en qué medida la participación del TC en el ejercicio del control concentrado de constitucionalidad ha contribuido a garantizar el derecho fundamental al trabajo, coadyuvando al desarrollo del constitucionalismo social dominicano a través de un efecto transformador de las relaciones laborales. 
En el Estado social dominicano, la actividad jurisprudencial de su TC puede contribuir a la construcción de indicadores, con el fin de determinar el estado actual en el que se encuentra esta corriente del constitucionalismo social, con énfasis en la garantía del derecho fundamental al trabajo.

\section{CONSTITUCIONALISMO SOCIAL}

\section{LATINOAMERICANO Y DOMINICANO}

El jurista italiano Zagrebelsky, respecto al concepto de constitucionalismo, lo considera como un término que sintetiza de manera más comprensiva, aunque como orientación general, muchos o quizás todos los ideales políticoconstitucionales del presente y del futuro, en una dimensión espacial y temporal cada vez más amplia. ${ }^{1}$

El constitucionalismo es una corriente ideológica que persigue limitar los poderes del Estado, delimitando su alcance dentro de los textos constitucionales, cuando se le conjuga con el aspecto social; se habla entonces del constitucionalismo social, refiriéndose a la vertiente que procura inscribir los derechos sociales en el contenido de las normas fundamentales.

El constitucionalismo social se expandió rápidamente por la región latinoamericana durante el siglo XIX. Entre algunos de los ejemplos más notables se pueden apreciar la Constitución de México de 1917, la Constitución de Cuba de 1940 y la Constitución de República Dominicana de 1963; esta última no pierde su relevancia a pesar de lo efímera que fue su vigencia.

En tal sentido, Gargarella señala que "la serie de reformas constitucionales que se llevaron adelante, en toda la región, desde México (1917) en adelante, fueron complejas y multidireccionales, pero, en todo caso, parece innegable que en ellas estuvo presente una clara impronta social". ${ }^{2}$ Por su parte, Carbonell y Ferrer señalan que "el surgimiento y consolidación de los derechos sociales, con todos los problemas y limitaciones que se quiera, es un aspecto propio de los ordenamientos jurídicos desarrollados, aquellos que han acogido —al menos como ideal— al paradigma del neoconstitucionalismo". ${ }^{3}$

1 Zagrebelsky, G., "Constitucionalismo", Revista Derechos y Libertades, vol. II, núm. 29, 2013, p. 20.

2 Gargarella, R., "El constitucionalismo latinoamericano y la "sala de máquinas" de la Constitución” (1980-2010), Argentina, Gaceta Constitucional, núm. 48, 2011, p. 290.

3 Carbonell, M., y Ferrer, E., Los derechos sociales y su justiciabilidad directa, México, Instituto de Investigaciones Jurídicas UNAM, 2014, p. 35. 
En términos generales, el derecho fundamental al trabajo ha fungido como punta de lanza para el reconocimiento de otros derechos sociales, propendiendo al desarrollo del constitucionalismo social y la inscripción de estos derechos en las normas fundamentales. Esta es una opinión corroborada también por Noguera y Navas quienes conciben al trabajo en el Estado social, como "el elemento fundante y determinante de la ciudadanía y del sistema de relaciones políticas y económicas". ${ }^{4}$

Para comprobar lo anterior, basta con mirar el contenido social de las constituciones latinoamericanas, las cuales incluyen en el canon constitucional el derecho fundamental al trabajo, tal y como se muestra en la tabla 1, a continuación.

\section{TABLA 1}

\begin{tabular}{|c|l|}
\hline País & \multicolumn{1}{|c|}{ Contenido social } \\
\hline Argentina & $\begin{array}{l}\text { Circunscribe el derecho al trabajo y la seguridad social dentro del } \\
\text { catálogo de derechos sociales que se encuentran en el texto cons- } \\
\text { titucional (artículos 14 al 17). }\end{array}$ \\
\hline Bolivia & $\begin{array}{l}\text { Incluyen el derecho al trabajo y la seguridad social dentro de los } \\
\text { derechos económicos y sociales (capítulo V, artículos del 33 al 71, } \\
75 \text { y siguiente). }\end{array}$ \\
\hline Brasil & $\begin{array}{l}\text { Dedica varios apartados específicamente al derecho al trabajo, la } \\
\text { libertad de asociación y derecho a huelga (artículos 7-11). }\end{array}$ \\
\hline Colombia & $\begin{array}{l}\text { Contienen disposiciones referentes a los derechos laborales del } \\
\text { trabajador y el bienestar social (artículos 50-74). }\end{array}$ \\
\hline Costa Rica & $\begin{array}{l}\text { Contiene disposiciones exclusivas al derecho al trabajo y la seguri- } \\
\text { dad social (artículos del 12 al 34). }\end{array}$ \\
\hline Cuba & $\begin{array}{l}\text { Las disposiciones del derecho del trabajo y a la seguridad social, se } \\
\text { encuentran en los artículos 32-70. }\end{array}$ \\
\hline Chile & $\begin{array}{l}\text { Los artículos 19 y 20 reconocen la libertad de trabajo, entre otras } \\
\text { prerrogativas. }\end{array}$ \\
\hline Ecuador & $\begin{array}{l}\text { En el catálogo de los derechos económicos y sociales (artículos 12 } \\
\text { al 34), se regulan el derecho al trabajo y la seguridad social. }\end{array}$ \\
\hline El Salvador & $\begin{array}{l}\text { Incluye el derecho del trabajo dentro del catálogo de los derechos } \\
\text { sociales de ese texto constitucional. }\end{array}$ \\
\hline
\end{tabular}

4 Noguera, A. y Navas, M., Los nuevos derechos de participación en Ecuador ¿derechos constituyentes o derechos constitucionales?, Valencia, España: Tirant lo Blanc, 2016, pp. 40 y 41. 


\begin{tabular}{|c|l|}
\hline País & \multicolumn{1}{|c|}{ Contenido social } \\
\hline Guatemala & $\begin{array}{l}\text { Este texto constitucional contiene disposiciones sobre el derecho } \\
\text { del trabajo y derechos de los empleados públicos. }\end{array}$ \\
\hline Honduras & $\begin{array}{l}\text { Contiene una sección para el derecho al trabajo (capítulo V, artícu- } \\
\text { los 127 al 141), de igual manera dedica varios artículos con dispo- } \\
\text { siciones sobre la seguridad social (artículos 142 al 144). }\end{array}$ \\
\hline México & $\begin{array}{l}\text { Contiene disposiciones sobre el derecho al trabajo, los empleados } \\
\text { privados y públicos (título VI, artículo 123). }\end{array}$ \\
\hline Nicaragua & $\begin{array}{l}\text { Dedica varios artículos a la regulación del derecho al trabajo (artí- } \\
\text { culos del 80 al 88). }\end{array}$ \\
\hline Panamá & $\begin{array}{l}\text { El capítulo tercero regula el derecho al trabajo, desde el artículo } \\
64 \text { al artículo 79. }\end{array}$ \\
\hline Paraguay & $\begin{array}{l}\text { Dedica un capítulo al derecho al trabajo (capítulo VIII, artículos } \\
86-106) .\end{array}$ \\
\hline Perú & $\begin{array}{l}\text { Contiene disposiciones generales sobre el derecho al trabajo (capí- } \\
\text { tulo II) y sobre los derechos de los empleados públicos (artículos } \\
39 \text { al 42). }\end{array}$ \\
\hline Uruguay & $\begin{array}{l}\text { Establece disposiciones para el derecho fundamental al trabajo y la } \\
\text { seguridad (artículos 53 al 57 y 67 al 71). }\end{array}$ \\
\hline Venezuela & $\begin{array}{l}\text { Incluye el derecho al trabajo como parte del catálogo de los dere- } \\
\text { chos sociales (capítulo V). }\end{array}$ \\
\hline
\end{tabular}

FUENTE: Elaboración a partir de la investigación del Doctor. Rafael Sánchez Vásquez.

En los textos constitucionales de América Latina, se ha inscrito el derecho al trabajo como un derecho fundamental, aunque se aprecian diferencias en cuanto a la amplitud del contenido entre el texto constitucional de un país y otro.

\section{CONSTITUCIONALIZACIÓN DEL DERECHO HUMANO AL TRABAJO EN REPÚBLICA DOMINICANA}

La primera vez que aparece la palabra "trabajo" en los textos constitucionales dominicanos ocurre en la Constitución de 1907, específicamente como la "libertad del trabajo" en el numeral 4 del artículo 9o. Esta concepción de la libertad del trabajo se mantuvo igual en la Constitución de 1908, pasando a ser el numeral 1 del artículo 6o. de esa carta magna e incluir también la libertad de la industria y del comercio. 
No es hasta 1934, durante la dictadura de Trujillo, cuando se aprecia en el texto constitucional una explicitación de la libertad del trabajo, al prohibirse el establecimiento de monopolios en beneficio de particulares (artículo 2o. numeral 6). Lo que lógicamente respondía a los intereses monopolistas que tenía el propio dictador. No obstante, durante la dictadura de Trujillo, el derecho del trabajo se fortaleció constitucional y legislativamente en el país, esto puede observarse en la ampliación de la libertad de trabajo, en el texto de la Constitución de 1942. En la reforma constitucional de 1947, el texto se mantuvo indemne.

Con el texto de la primera Constitución social de la República Dominicana, proclamada el 29 de abril de 1963 durante el gobierno del profesor Juan Bosch, se produjo el primer hito referente al aspecto constitucional del derecho humano al trabajo en la República Dominicana, al consagrar el trabajo como fundamento principal de la existencia de la nación.

En la reforma constitucional de 1966 ocurrió una involución respecto al desarrollo del derecho fundamental al trabajo, al desconocerse muchas de las prerrogativas que habían sido alcanzadas con la Constitución de 1963; es decir, se produjo una contrarreforma que afectó el desarrollo de este derecho fundamental en República Dominicana. La reforma constitucional de 1994, a pesar de haber introducido grandes cambios en el sistema de justicia dominicano, mantuvo las mismas prerrogativas fundamentales respecto al derecho del trabajo que se encontraban en la Constitución de 1966.

Estas prerrogativas continuaron presentes en la reforma constitucional del año 2002, sin ampliarse su contenido. No es hasta 2010, cuando se inicia nuevamente otra etapa relevante del constitucionalismo social dominicano, en el reconocimiento de los derechos constitucionales de carácter laboral, al establecer en su artículo 62 el derecho fundamental al trabajo.

En el devenir histórico que conllevó a la inscripción del derecho al trabajo como un derecho fundamental, se aprecia la influencia tanto de la Constitución en las normas laborales, como viceversa. Con la consagración del derecho humano al trabajo, dentro de las normas constitucionales, surge la pregunta: ¿constitucionalización o laboralización? Específicamente, con la Constitución de Querétaro podemos decir que comienza la laboralización de la Constitución. Un fenómeno sociojurídico que devendría en la constitucionalización del derecho humano al trabajo.

Con la Constitución de 2010 se produce otra de las grandes trasformaciones en cuanto a este derecho fundamental, es la adopción del derecho al trabajo, un tanto diferente a la concepción común que aparecía en las constituciones dominicanas previas. El derecho fundamental al trabajo deriva de 
la disposición del artículo 6o. numeral 1 del Pacto Internacional de los Derechos Económicos, Sociales y Culturales.

Comúnmente se recurre al derecho del trabajo como ciencia social para el análisis de las relaciones laborales entre los empleadores y trabajadores, así como para la garantía del derecho humano al trabajo. Es innegable que lo laboral tiene un marcado matiz social y a la vez jurídico, de ahí que el trabajo tenga tanta preminencia en la determinación del grado de justicia social en el que se encuentra un Estado constitucional.

\section{CONTROL DE CONSTITUCIONALIDAD EN EL ESTADO SOCIAL Y DEMOCRÁTICO DE DERECHO DOMINICANO}

La creación del TC generó - tanto antes como después- muchos debates entre los doctrinarios y juristas dominicanos, haciéndose eco de las discusiones jurídicas que se suscitaran, entre Hans Kelsen y Carl Schmitt, sobre quién debe ser el garante de la Constitución, pero respecto al ejercicio del control de constitucionalidad.

El control de constitucionalidad contribuye a garantizar la supremacía de la Constitución, la cual se hace viable a través de la labor del TC. No obstante, el control de constitucionalidad se manifiesta de diversas formas: concentrado y difuso. El control difuso es de origen occidental, cuyo génesis se remonta al judicial review americano. El control concentrado es de origen europeo.

La garantía jurisdiccional es sine qua non para la protección efectiva de los derechos fundamentales; debido a que éstos son derechos justiciables. A pesar de que los tribunales ejercen un control difuso de la constitucionalidad, por medio del cual están obligados a observar las disposiciones que establece la Constitución al momento de dirimir un conflicto, sus decisiones — expresadas a través de sentencias - no tienen efecto erga omnes. Ahora bien, el control concentrado de la constitucionalidad sí produce efectos erga omnes.

Este control concentrado en el Estado de derecho dominicano se dispuso por primera vez en el año 1924 y correspondió a la Suprema Corte de Justicia. No obstante, este control concentrado fue efímero, pues sólo estuvo vigente hasta el año 1927. Posteriormente, con la Constitución del año 1994 se instaura nuevamente el control concentrado mediante un sistema mixto, tanto el control difuso como el control concentrado por parte de la Suprema Corte de Justicia.

Con la Constitución de 2010, también se introdujeron cambios significativos en el control de constitucionalidad en República Dominicana, ya que el control concentrado pasó exclusivamente al TC. 


\section{Tribunal Constitucional y protección jurisdiccional del derecho fundamental al trabajo}

A pesar del precedente que marcó la instauración del TC, este órgano jurisdiccional no entró en funcionamiento sino hasta el año 2012. Por lo que se tomará el primer cuatrienio de su funcionamiento (hasta 2015) para analizar la actividad jurisdiccional en la defensa del derecho social y fundamental al trabajo, con el propósito de obtener una mejor comprensión del fenómeno sociojurídico que se analiza.

El jurista Fix-Zamudio destaca que

...los tribunales deben desarrollar los principios constitucionales y la legislación social, tarea básica, puesto que son los propios tribunales, especialmente los de carácter supremo, y todavía con mayor fuerza, si están especializados en materia constitucional (cortes o tribunales constitucionales), que poseen la capacidad de desarrollar los postulados de justicia social, a través de la aplicación efectiva de los principios de carácter fundamental. ${ }^{5}$

Esta labor que señala el jurista Fix-Zamudio se concretiza en la jurisprudencia, ya que ésta permite el estudio del derecho vivo y actual con conocimiento del pasado. Si conocemos la jurisprudencia, conoceremos hacia dónde se encamina la administración de justicia de un país. En el caso que nos ocupa, el estatus de la protección de los derechos fundamentales de carácter laboral.

En la tabla 2 se presentan algunas decisiones desde 1997 hasta el 2009, en materia de control concentrado de constitucionalidad, que establecieron precedentes constitucionales en defensa del derecho fundamental al trabajo por parte de la Suprema Corte de Justicia.

\section{TABLA 2}

\begin{tabular}{|c|l|}
\hline Sentencia & \multicolumn{1}{|c|}{ Precedente jurisprudencial } \\
\hline $\begin{array}{c}\text { Sentencia del 22 } \\
\text { de septiembre de 1999 }\end{array}$ & $\begin{array}{l}\text { El artículo 712 del Código de Trabajo no contraviene } \\
\text { las disposiciones de la Constitución. }\end{array}$ \\
\hline $\begin{array}{c}\text { Sentencia del 30 } \\
\text { de noviembre de 2000 }\end{array}$ & $\begin{array}{l}\text { La libertad de trabajo no resulta afectada cuando el } \\
\text { legislador impone condiciones para el ejercicio de la } \\
\text { profesión liberal. }\end{array}$ \\
\hline
\end{tabular}

5 Fix-Zamudio, H. et al., El constitucionalismo en las postrimerías del siglo XX, t. V: La Constitución mexicana. 70 años después, México, UNAM, 1988, p. 82. 


\begin{tabular}{|c|l|}
\hline Sentencia & \multicolumn{1}{|c|}{ Precedente jurisprudencial } \\
\hline $\begin{array}{c}\text { Sentencia del 9 } \\
\text { de febrero de 2000 }\end{array}$ & $\begin{array}{l}\text { Las disposiciones del artículo 539 del Código de Tra- } \\
\text { bajo no contravienen la Constitución. }\end{array}$ \\
\hline $\begin{array}{c}\text { Sentencia del 23 } \\
\text { de agosto de 2000 }\end{array}$ & $\begin{array}{l}\text { Declara la inconstitucionalidad del artículo 11 de la } \\
\text { Ley núm. 374-98. }\end{array}$ \\
\hline & $\begin{array}{l}\text { Establece que una norma jurídica nueva no puede mo- } \\
\text { dificar el estatus jurídico de los derechos adquiridos, } \\
\text { pero, por el contrario, las simples expectativas están } \\
\text { de agosto de 2008 } \\
\end{array}$ \\
& $\begin{array}{l}\text { sujetas a todas las contingencias y a todos los cambios } \\
\text { de legislación. }\end{array}$ \\
\hline
\end{tabular}

FUENTE: Elaboración propia a partir de la compilación de 12 años de justicia constitucional en República Dominicana.

Tal y como se observa en la tabla 2, en un lapso de 12 años en materia de justicia constitucional, la Suprema Corte de Justicia solamente dictó cinco precedentes jurisprudenciales constitucionales en materia laboral.

En la opinión del Dr. Milton Ray Guevara, presidente del TC dominicano:

...el constitucionalismo social ha tenido un impacto importante en el derecho humano al trabajo, vinculándolo inclusive a la aparición de los tribunales constitucionales, tales como: el Tribunal Constitucional de Austria (1920), el Tribunal Constitucional de Polonia (1921), el Tribunal Constitucional de Yugoslavia (1921) y el Tribunal de Garantías Constitucionales de España (1931); debido al desarrollo de los derechos de la segunda generación y el acoplamiento de la Constitución con esos derechos sociales. ${ }^{6}$

En el año 2010, al tenor de las disposiciones de la Constitución en sus artículos 184 y 185, el control concentrado de constitucionalidad pasó al TC dominicano; es decir, se especializa aún más con la creación de una jurisdicción encargada de ejercer la justicia constitucional, que consiste en ${ }^{7}$

...la potestad del Tribunal Constitucional y del Poder Judicial de pronunciarse en materia constitucional en los asuntos de su competencia. Se realiza

6 Ray, M., Opinión Constitucional, Santo Domingo, Amigo del Hogar, 2014, p. 567.

7 Según establece el artículo 5o. de la Ley núm. 137-11, Orgánica del Tribunal Constitucional y de los Procedimientos Constitucionales, Gaceta Oficial, núm. 10622, 13 de junio de 2011. 
mediante procesos y procedimientos jurisdiccionales que tienen como objetivo sancionar las infracciones constitucionales para garantizar la supremacía, integridad y eficacia y defensa del orden constitucional, su adecuada interpretación y la protección efectiva de los derechos fundamentales" [en nuestro caso particular del derecho fundamental al trabajo].

Este suceso se constituye como un catalizador del desarrollo y defensa del derecho fundamental al trabajo, como veremos más adelante, en virtud de que las decisiones $^{8}$ del TC son definitivas, irrevocables y constituyen precedentes vinculantes para los poderes públicos y todos los órganos del Estado.

En la tabla 3 se muestran los recursos de revisión constitucional de decisiones jurisdiccionales sometidas al TC durante 2014.

\section{TABLA 3}

\begin{tabular}{|c|l|}
\hline Sentencia & \multicolumn{1}{|c|}{ Referencia } \\
\hline TC/0037/14 & $\begin{array}{l}\text { Revisión constitucional de la sentencia núm. 342, de fecha 16/06/2012, } \\
\text { dictada por la Tercera Sala de la Suprema Corte de Justicia. }\end{array}$ \\
\hline TC/0046/14 & $\begin{array}{l}\text { Demanda de suspensión de ejecución de la sentencia núm. 329, } \\
\text { de fecha } 12 / 06 / 2013, \text { dictada por la Tercera Sala de la Suprema } \\
\text { Corte de Justicia. }\end{array}$ \\
\hline TC/0069/14 & $\begin{array}{l}\text { Demanda en suspensión de ejecución de la sentencia núm. 229, } \\
\text { de fecha 24/04/2013, dictada por la Tercera Sala de la Suprema } \\
\text { Corte de Justicia. }\end{array}$ \\
\hline TC/0115/14 & $\begin{array}{l}\text { Demanda de suspensión de ejecución de la sentencia núm. 444, } \\
\text { de fecha 26/10/2011, dictada por la Tercera Sala de la Suprema } \\
\text { Corte de Justicia. }\end{array}$ \\
\hline TC/0124/14 & $\begin{array}{l}\text { Revisión constitucional de la Sentencia núm. 606, de fecha 19/09/2016, } \\
\text { dictada por la Tercera Sala de la Suprema Corte de Justicia. }\end{array}$ \\
\hline TC/0141/14 & $\begin{array}{l}\text { Revisión constitucional de la sentencia núm. 478, de fecha 25/07/2012, } \\
\text { dictada por la Tercera Sala de la Suprema Corte de Justicia. }\end{array}$ \\
\hline TC/0148/14 & $\begin{array}{l}\text { Demanda en suspensión de ejecución de la sentencia núm. 165, } \\
\text { de fecha 26/03/2013, dictada por la Tercera Sala de la Suprema } \\
\text { Corte de Justicia. }\end{array}$ \\
\hline TC/0175/14 & $\begin{array}{l}\text { Revisión constitucional de la sentencia núm. 505, de fecha 01/08/2012, } \\
\text { dictada por la Tercera Sala de la Suprema Corte de Justicia. }\end{array}$ \\
\hline
\end{tabular}

8 Según establece el artículo 184 de la Constitución de la República Dominicana. 


\begin{tabular}{|c|l|}
\hline Sentencia & \multicolumn{1}{|c|}{ Referencia } \\
\hline TC/0175/14 & $\begin{array}{l}\text { Revisión constitucional de la sentencia núm. 505, de fecha 01/08/2012, } \\
\text { dictada por la Tercera Sala de la Suprema Corte de Justicia. }\end{array}$ \\
\hline TC/0198/14 & $\begin{array}{l}\text { Revisión constitucional de la sentencia núm. 82 y la resolución núm. } \\
7926-2012, \text { de fecha 22/02/2012 y 30/10/2012, dictadas por la } \\
\text { Tercera Sala de la Suprema Corte de Justicia. }\end{array}$ \\
\hline TC/0211/14 & $\begin{array}{l}\text { Demanda de suspensión de ejecución, de la sentencia núm. } \\
786, \text { de fecha 18/12/2013, dictada por la Tercera Sala de la } \\
\text { Suprema Corte de Justicia. }\end{array}$ \\
\hline TC/0250/14 & $\begin{array}{l}\text { Demanda en suspensión de ejecución, la sentencia núm. 175, } \\
\text { de fecha 26/03/2014, dictada por la Tercera Sala de la Suprema } \\
\text { Corte de Justicia. }\end{array}$ \\
\hline TC/0308/14 & $\begin{array}{l}\text { Acción directa de inconstitucionalidad contra la ley núm. 187- } \\
\text { 2007, sobre pasivo laboral. }\end{array}$ \\
\hline TC/0319/14 & $\begin{array}{l}\text { Revisión constitucional de la sentencia núm. 62, de fecha 20/02/2013, } \\
\text { dictada por la Tercera Sala de la Suprema Corte de Justicia. }\end{array}$ \\
\hline TC/0329/14 & $\begin{array}{l}\text { Demanda en suspensión de ejecución de la sentencia núm. 678, } \\
\text { de fecha 24/10/2012, dictada por la Tercera Sala de la Suprema } \\
\text { Corte de Justicia. }\end{array}$ \\
\hline TC/0343/14 & $\begin{array}{l}\text { Revisión constitucional de la sentencia núm. 318, de fecha 23/05/2012, } \\
\text { dictada por la Tercera Sala de la Suprema Corte de Justicia. }\end{array}$ \\
\hline TC/0397/14 & $\begin{array}{l}\text { Revisión constitucional de la sentencia núm. 73, de fecha 20/02/2013, } \\
\text { dictada por la Tercera Sala de la Suprema Corte de Justicia. }\end{array}$ \\
\hline TC/0400/14 & $\begin{array}{l}\text { Revisión constitucional de la resolución núm. 2874-2013, de fecha } \\
\text { 21/08/2013, dictada por la Tercera Sala de la Suprema Corte de } \\
\text { Justicia. }\end{array}$ \\
\hline
\end{tabular}

FUENTE: Elaboración propia a partir de las sentencias del Tribunal Constitucional dominicano.

La tabla 3 nos permite tener una idea de la cantidad de decisiones que han sido revisadas por el TC, procedentes de órganos jurisdiccionales del orden laboral o relacionadas con la legislación laboral, notándose una mayoría de las revisiones constitucionales de las decisiones jurisdiccionales — señaladas con cursivas dentro de la tabla-.

Desde la entrada en funcionamiento del TC, hasta la fecha, se pueden apreciar al menos ocho precedentes constitucionales en materia laboral, en las decisiones: TC/0059/12, TC/0071/12, TC/0179/13, TC/0203/13, TC/0308/14, TC/0435/15, TC/0489/15 y TC/0563/15. Lo que denota la 
importancia de la actividad jurisdiccional del TC e impacto en las relaciones jurídicas derivadas del derecho fundamental al trabajo, si se le compara a la actividad de la Suprema Corte de Justicia, durante el tiempo que ejerció el control concentrado de constitucionalidad, cuyos precedentes más relevantes aparecen en la tabla 2 de este artículo.

\section{ACTIVIDAD JURISDICCIONAL DEL TRIBUNAL CONSTITUCIONAL EN MATERIA LABORAL DURANTE 2012}

En su primer año de actividad jurisdiccional, el TC dictó once decisiones relacionadas con la materia laboral, lo que representó para ese año una tasa de $10.57 \%$ de los conflictos dirimidos por esa jurisdicción. En el año 2012, la mayor parte de los conflictos dirimidos por la jurisdicción constitucional $(54.55 \%)$, derivaron de relaciones laborales de carácter privado, tan sólo el $45.45 \%$ procedieron de relaciones laborales de carácter público.

En el gráfico 1 se presenta la actividad de la jurisprudencia constitucional en materia laboral de 2012, relacionada con el control de constitucionalidad.

\section{GRÁFICO 1. JURISPRUDENCIA CONSTITUCIONAL EN MATERIA LABORAL 2012}

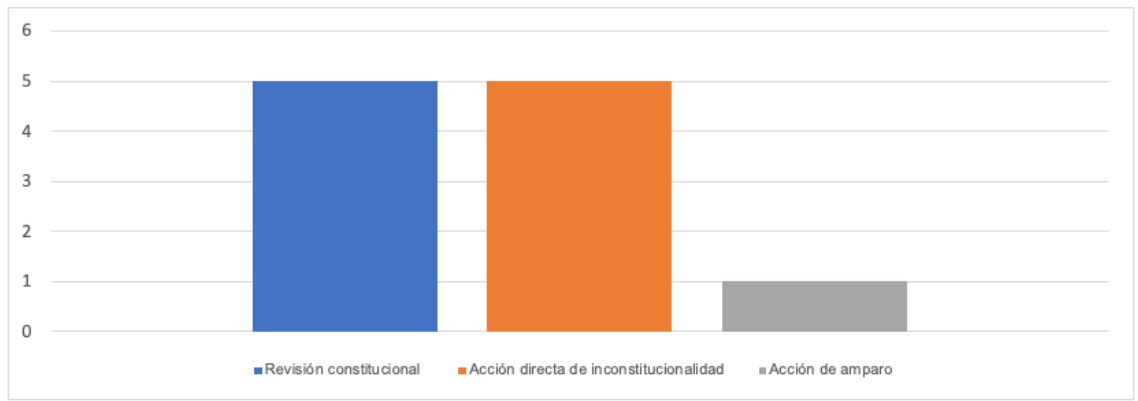

FUENTE: Elaboración propia.

Tal como se puede apreciar en la estadística del gráfico 1, respecto al modo del control de constitucionalidad que hizo posible el dictamen de la sentencia —en el génesis - de la actividad jurisdiccional del TC; la revisión constitucional de las decisiones jurisprudenciales y la acción directa de inconstitucio- 
nalidad de normas laborales fueron los medios más utilizados por los sujetos del derecho de trabajo.

Al lado de lo anterior, es menester identificar dentro del contenido de las decisiones judiciales en materia laboral del año 2012, el comportamiento de los derechos específicos fundamentales de carácter laboral reclamados ante la jurisdicción constitucional, con la finalidad de obtener una mejor aprehensión del impacto de las relaciones laborales.

En virtud de ello, en el gráfico 2 se muestran los contenidos específicos reclamados ante el $\mathrm{TC}$, respecto a las 11 decisiones dictadas.

\section{GRÁFICO 2. DERECHOS ESPECÍFICOS FUNDAMENTALES DE CÁRACTER LABORAL RECLAMADOS EN LA SENTENCIAS DEL TC EN 2012}

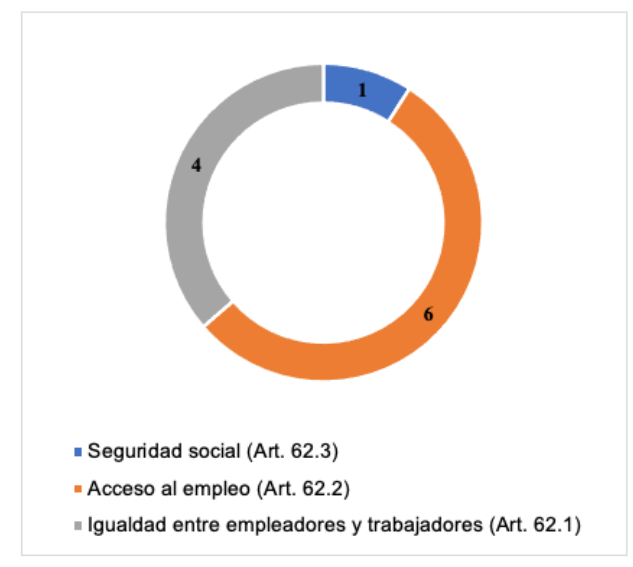

FUENTE: Elaboración propia.

En 2012, la prerrogativa del acceso al empleo y la igualdad entre los empleadores y trabajadores fueron las que procuraron obtener una mayor protección constitucional, dejando en última instancia la seguridad social. De una manera segregada, estos aspectos correspondieron a las siguientes decisiones: la seguridad social en la sentencia TC/0012/12; el acceso al empleo en las sentencias TC/0018/12, TC/0019-2012, TC/0048/12, TC/0085/12, TC/0089/2012, TC/0096/12; y la igualdad entre empleadores y trabajadores en las sentencias TC/0022-2012, TC/0059/2012, y TC/0071/2012.

De igual importancia, las sentencias más relevantes en materia laboral durante 2012 son las siguientes: 
- En la sentencia TC/0012/129 el TC estableció una reinterpretación del artículo 252 de la Ley núm. 873, declarando que la interpretación constitucional de dicho artículo debe ser la siguiente: “Tendrá derecho a pensión el o la sobreviviente de un matrimonio o de una unión marital de hecho con por lo menos un año de duración, salvo el caso de que hayan engendrado hijos o que el fallecimiento hubiere sido causado por un accidente o por las causales del artículo 247”. Esta sentencia benefició a todos los cónyuges de miembros de las Fuerzas Armadas.

- En la sentencia TC/0018/12,10 el Tribunal Constitucional dispuso que "el Procurador General de la República: a) Tome las medidas que considere pertinentes para establecer en los recintos de detención localizados en los palacios de justicia y en los establecimientos policiales donde no exista el protocolo de entrada y salida de los defensores públicos y de los abogados en general, con la finalidad de que éstos puedan ofrecer la asistencia legal que requieran los detenidos, sin perjuicio de su integridad y seguridad físicas; b) Ordene, específicamente al Procurador Fiscal del Distrito Judicial Duarte, así como a los demás miembros del Ministerio Público que tengan bajo su responsabilidad recintos preventivos de detención en todo el territorio nacional, que mientras se elabore y ponga en vigencia el protocolo más arriba descrito, permitan a los defensores públicos y a los abogados, el acceso al recinto correspondiente, previa acreditación de sus calidades".

- En la sentencia TC/0022/12,11 el TC declaró el apego a la carta fundamental de la Ley núm. 6186, de Fomento Agrícola del 12 de febrero de 1963 estableciendo que "el procedimiento especial que traza la ley sobre fomento agrícola tiene como propósito de establecer las condiciones más adecuadas para garantizar la sostenibilidad del fomento del crédito territorial, puntal trascendente del crecimiento económico nacional".

9 Esta sentencia emanó a partir de la revisión constitucional de la sentencia núm. 1562011, dictada por el Tribunal Superior Administrativo, incoada por Lauriana Villar contra la Junta de Retiro de las Fuerzas Armadas, con la finalidad de obtener la pensión como conviviente de su fenecido esposo, quien laboró en las Fuerzas Armadas.

10 La misma surgió a partir del reclamo de unos defensores públicos a quienes no se le permitía el acceso a un recinto carcelario, a fin de dar asistencia legal a los detenidos; no permitiéndoles ejercer su derecho al trabajo como defensores públicos. Esta sentencia benefició a las partes interesadas y a todos los defensores públicos de la República Dominicana.

11 La parte recurrente en esta decisión se fundamentaba en que la Ley núm. 6186 creaba desigualdad entre los hombres, dando preminencia a los créditos laborales. 
- En la sentencia TC/0059/2012, el TC declaró la conformidad con la Constitución del artículo 539 del Código de Trabajo, al determinar que dicha disposición de la ley núm. 16-92 no violenta la ley fundamental, pues este artículo establece que el derecho al recurso se ejercerá de conformidad con la ley.

- En la sentencia TC/0071/12, ${ }^{12}$ el TC declaró inadmisible una acción directa de inconstitucionalidad contra la ordenanza núm. 28-2000-44, de fecha 03/05/2000, dictada por la Corte de Trabajo del Distrito Nacional, en atribuciones de juez de los referimientos; estableciendo que las decisiones judiciales no son susceptibles de control directo de inconstitucionalidad, sino de revisión constitucional.

- En la sentencia TC/0085/12, ante el reclamo de un exmiembro de la Policía Nacional (señor Alberto Rodríguez), con la finalidad de revocar la Orden General núm. 079-2010, de fecha 14/10/2010, que ordenó la cancelación de su nombramiento como primer teniente de la Policía Nacional; la jurisdicción constitucional declaró su incompetencia por tratarse de un asunto de competencia de la jurisdicción contenciosoadministrativa, en virtud de las disposiciones del artículo 75 de la ley núm.137-11.

- En la sentencia TC/0096/12, respecto al pago de salario por el trabajo realizado al señor Belisario Martínez, en su condición de regidor del Ayuntamiento de Nagua, el TC estableció que se trataba de un amparo de cumplimiento, a la luz del artículo 104 de la ley núm. 137-11, indicando que debe respetarse el derecho del accionante a: "La igualdad y la no discriminación al ejercer un trabajo, sin que importe su naturaleza, deben prevalecer en toda entidad, máxime si se trata de un ciudadano que fue electo y designado conforme a la ley y ha desempeñado debidamente sus funciones".

\section{ACTIVIDAD JURISDICCIONAL DEL TRIBUNAL CONSTITUCIONAL EN MATERIA LABORAL DURANTE 2013}

Durante 2013, el TC emitió la cantidad de 44 decisiones constitucionales en materia laboral, que procedieron tanto de relaciones laborales de carácter

12 Este primer precedente fue utilizado en el análisis de otras sentencias constitucionales de carácter laboral por parte del TC, tales como la TC/0072/12 y la TC/0089/12. 
privado como de carácter público. En este año la mayor parte de las demandas en protección del derecho fundamental al trabajo, emanaron de relaciones laborales de carácter público.

En el gráfico 3 aparece la jurisprudencia constitucional en materia laboral durante 2013, segregada por el modo en que el Tribunal Constitucional ejerció el control de constitucionalidad.

\section{GRÁFICO 3. JURISPRUDENCIA CONSTITUCIONAL EN MATERIA LABORAL 2013}

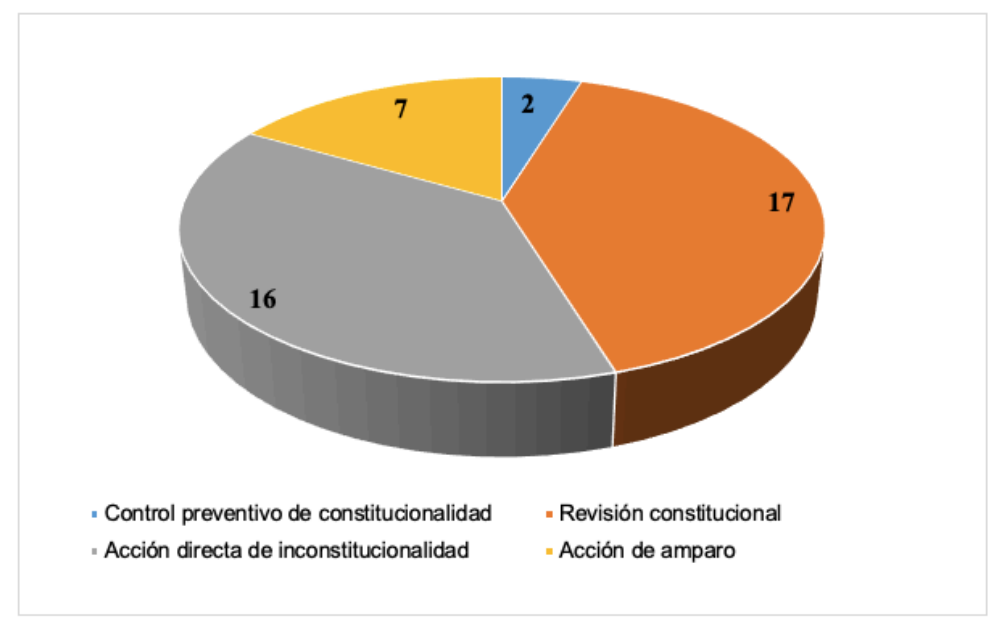

FUENTE: Elaboración propia.

Tal como se vislumbra en el gráfico 3, en 2013 las revisiones constitucionales aumentaron ligeramente respecto a las acciones directas de inconstitucionalidad, en contraste con el 2013 cuando estuvieron en la misma proporción. Este fenómeno encuentra respuesta en el precedente constitucional establecido mediante la sentencia TC/0071/12,13 lo que también incidió para que aumentara las acciones de amparo solicitando la suspensión de ejecución de sentencias laborales.

De igual forma, las sentencias más destacadas en materia laboral durante el año 2013 son las siguientes:

13 Esta decisión estableció que las decisiones judiciales no son susceptibles de control directo de inconstitucionalidad, sino de revisión constitucional. 
- En la sentencia TC/0027/13, el TC determinó que una ficha penal no retirada a un ciudadano se convierte una conculcación que afecta el derecho al trabajo de las personas, el acceso al crédito y el derecho al honor. En la sentencia TC/0080/13 se confirmó nuevamente este criterio, al establecer que el no levantamiento de una ficha afecta el derecho de acceder al trabajo.

- La sentencia TC/0153/13 declaró conforme a la Constitución la parte in fine del artículo $715^{14}$ del Código de Trabajo, por considerar que no resulta violatorio al principio de separación de poderes, ni a la regla de la incompatibilidad de la función judicial con otros cargos públicos; luego de analizar la validez del fiscalizador laboral como funcionario que presta su servicio dentro del Ministerio de Trabajo, para las infracciones penales-laborales.

- La sentencia TC/0155/13 declaró conforme a la Constitución el artículo 539 del Código de Trabajo (ley núm. 16-92), por no resultar violatoria a la facultad constitucional de las cortes de apelación para conocer de los recursos de apelación. Esta decisión confirma el criterio adoptado por el TC en su decisión TC/0059/12.

- Mediante la sentencia TC/0190/1315 el TC declaró no conforme con la Constitución los artículos 2o., 3o., 4o., 5o. y 6o. de la ley núm. 374-98, que creó el Fondo Nacional de Pensiones y Jubilaciones de los Trabajadores Metalmecánicos, de la Industria Metalúrgica y Minera, por violar los principios de igualdad, legalidad, justicia y equidad tributaria, dispuestos en los artículos 18, 62.4 y 243 de la Constitución y el bloque de constitucionalidad, "al establecer un régimen de doble cotización a cargo de los empleadores y trabajadores del sector metalmecánico, metalúrgico y minero".

- El TC, a través de su sentencia TC/0203/13, del 13 de noviembre de 2013, estableció que: "que el derecho a la seguridad social, en particular de las personas envejecientes y que sufren de alguna discapacidad, se en-

14 La parte in fine del artículo 715 establece que: “(...) En el Distrito Nacional y en el Distrito Judicial de Santiago, el ministerio público será ejercido por un abogado al servicio de la Secretaría de Estado de Trabajo".

15 En tal sentido, ordenó a las entidades de intermediación financiera que operen en el territorio nacional la congelación de los bienes financieros y económicos pertenecientes al Fondo Nacional de Pensiones y Jubilaciones de los Trabajadores Metalmecánicos, hasta que los mismos sean intervenidos por el Consejo Nacional de Seguridad Social, la Superintendencia de Pensiones y la Tesorería de la Seguridad Social. 
cuentra revestido de la fuerza que aporta el texto supremo, que lo hace de cumplimiento obligatorio, máxime porque el derecho a la seguridad social responde también al principio de progresividad consagrado en el artículo 81 de la Constitución".

- Sentencia TC/0229/13, relativa al control preventivo de constitucionalidad del "Convenio de Seguridad Social suscrito entre los Gobiernos de la República Dominicana y la República del Ecuador”. ${ }^{16}$ Con esta decisión el TC ejerció el control preventivo de constitucionalidad, declarándolo conforme a la Constitución y centrando su atención a "examinar los siguientes aspectos de la convención: i) ámbito de aplicación del Convenio, ii) personal diplomático, iii) trabajadores a bordo de una nave o aeronave; iv) protección de información, y v) solución de controversias. El Convenio establece en cuanto a la legislación aplicable, que el trabajador estará sometido a la legislación de la seguridad social de cada parte contratante, independientemente del Estado en el que, este resida o del Estado en que el empleador tenga su sede".

\section{ACTIVIDAD JURISDICCIONAL DEL TRIBUNAL CONSTITUCIONAL EN MATERIA LABORAL DURANTE EL 2014}

Respecto al año 2014, la cantidad de sentencias referentes a la materia laboral disminuyó cuantitativamente, llegando a un total de 31 decisiones. En ese mismo sentido, la tasa con relación a la cantidad total de decisiones en ese año también disminuyó.

Por otra parte, al tercer año de su actividad jurisdiccional —2014 , el $70.96 \%$ de los conflictos dirimidos por el TC provinieron de relaciones laborales de carácter público. En el gráfico 4 se muestra la jurisprudencia constitucional en materia laboral durante 2014, clasificada según el modo en que el TC ejerció el control de constitucionalidad.

En el gráfico 4 se puede apreciar claramente el aumento cuantitativo de las revisiones constitucionales de las decisiones jurisdiccionales de carácter laboral, de esta manera se confirma la tendencia creciente del uso de esta forma de ejercicio de control de constitucionalidad, a la par de la solicitud

16 En fecha 22 de abril de 2013, el TC ejerció el control preventivo de constitucionalidad, declarando conforme a la Constitución dicho convenio. 
de suspensión de ejecución de sentencias y las acciones directas de inconstitucionalidad.

\section{GRÁFICO 4. JURISPRUDENCIA CONSTITUCIONAL EN MATERIA LABORAL 2014}

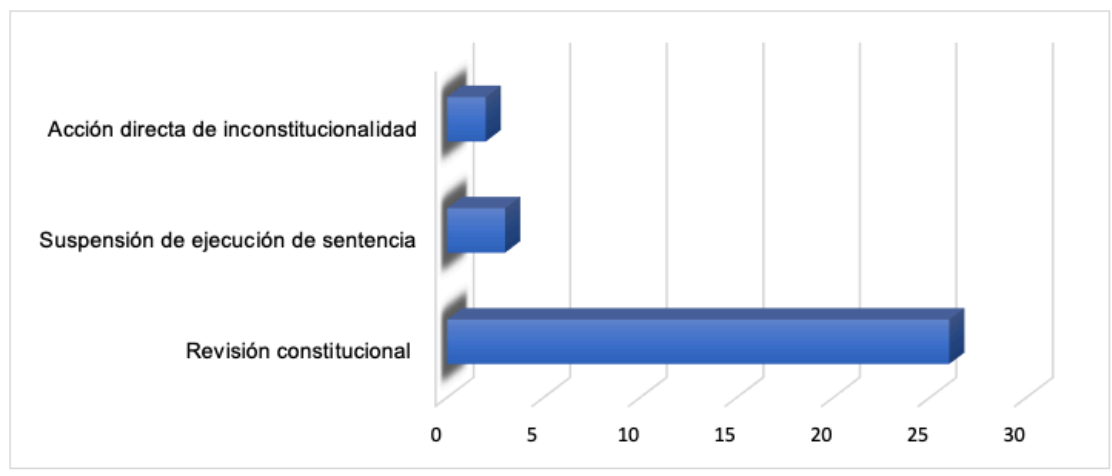

FUENTE: Elaboración propia

Las sentencias más destacadas en materia laboral durante el año 2014 fueron las siguientes:

- La sentencia TC/308/14, referente a una acción directa de inconstitucionalidad contra la ley sobre el pasivo laboral, núm. 187-07, de fecha 6 de agosto de 2007. El TC rechazó esta acción en virtud de que la Suprema Corte de Justicia la había declarado de conformidad con la Constitución, específicamente en aplicación del artículo 27717 de la carta magna.

- Con la sentencia TC/165/14, el TC estableció que a pesar de que al trabajador no se le retribuyera el pago de sus salarios, ni tampoco se le reconociera el derecho a recibir el pago de vacaciones y su salario

17 El artículo 277 de la Constitución dispone que: "Todas las decisiones judiciales que hayan adquirido la autoridad de la cosa irrevocablemente juzgada, especialmente las dictadas en ejercicio del control directo de la constitucionalidad por la Suprema Corte de Justicia, hasta el momento de la proclamación de la presente Constitución, no podrán ser examinadas por el Tribunal Constitucional y las posteriores estarán sujetas al procedimiento que determine la ley que rija la materia". 
de Navidad, no puede constituir una justificación para sustraerse del procedimiento establecido, o sea, el Código de Trabajo, el cual ofrece a todo trabajador los más elevados niveles de seguridad y protección jurídica.

- Mediante la sentencia TC/151/14, reiteró el criterio establecido en sus sentencias TC/0058/12 y TC/0273/13, estableciendo que la figura de la suspensión de las decisiones recurridas no puede convertirse en una herramienta para impedir que los procesos judiciales lleguen a su conclusión, por lo que es necesario que se demuestre fehacientemente la posibilidad de que ocurra un daño realmente irreparable, con la finalidad de evitar que esa jurisdicción constitucional especializada sea convertida en un nuevo grado de jurisdicción para ventilar asuntos que no reúnen méritos suficientes para serlo.

- A través de la sentencia TC/375/14, dispuso que, aun cuando el artículo 256 de la Constitución prohíbe el reintegro de los miembros de las fuerzas armadas luego de ser cancelados, ciertamente el mencionado texto constitucional no es aplicable cuando la cancelación adolece de irregularidad, es arbitraria y violenta derechos fundamentales tales como el derecho al trabajo y al honor.

\section{ACTIVIDAD JURISDICCIONAL \\ DEL TC EN MATERIA LABORAL \\ DURANTE EL 2015}

En 2015 se emitieron 67 sentencias constitucionales relacionadas con la protección del derecho fundamental al trabajo. El 56.71\% de estas decisiones derivaron de relaciones laborales de carácter público. En cuanto al resto - el 43.28\%—, tuvieron su origen en conflictos laborales de carácter privado.

En el gráfico 5 aparece la jurisprudencia constitucional en materia laboral durante 2015, catalogada según la forma en que el TC ejerció el control de constitucionalidad.

Asimismo, tal como se aprecia en el gráfico 5, la cantidad de sentencias aumentaron cuantitativamente en 2015, prevaleciendo la revisión constitucional como modo más utilizado para el ejercicio del control de constitucionalidad por parte de los ciudadanos. 


\section{GRÁFICO 5. JURISPRUDENCIA CONSTITUCIONAL EN MATERIA LABORAL 2015}

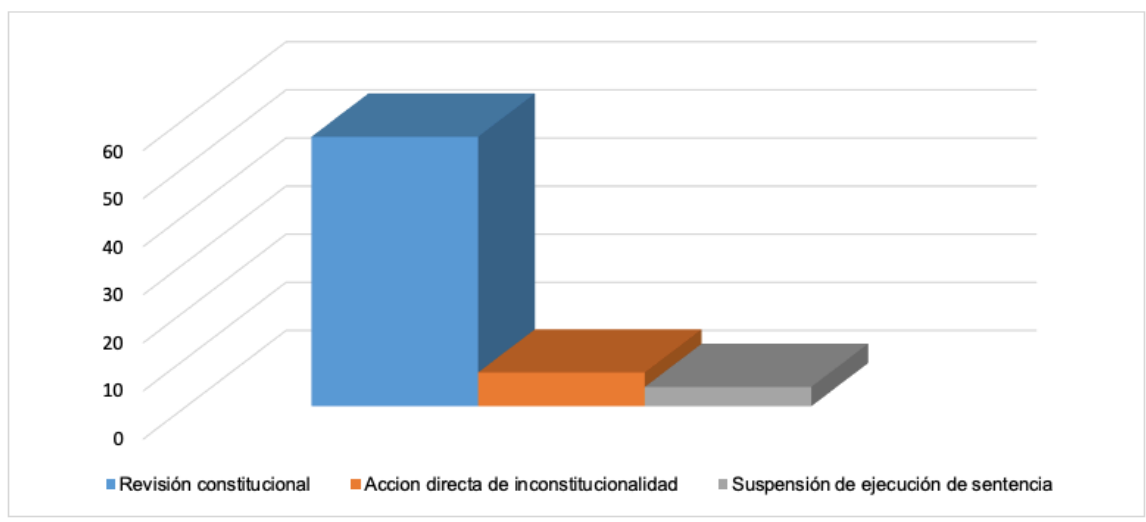

FUENTE: Elaboración propia.

De las decisiones constitucionales en materia laboral de 2015, cabe resaltar las siguientes:

- Con la sentencia TC/0435/15, el TC declaró conforme con, la Constitución los párrafos II y III del artículo 31 de la Ley núm. 87-01, que establecen que las administradoras de riesgos de salud tendrán a su cargo a todos los trabajadores del sector privado, formal o informal, no subsidiados que las seleccionen, al considerar que estas dos disposiciones no violan los derechos fundamentales a la igualdad (artículo 39.1) y la libertad de empresa (artículo 50.1), al excluir a los trabajadores del sector público de dicha selección, ya que la misma ley sustantiva permite el establecimiento de monopolios en provecho del Estado.

- Mediante la sentencia interpretativa-exhortativa TC/489/15, el TC declaró no conforme a la Constitución el artículo 5o., párrafo II, acápite c), de la Ley núm. 491-08, que modifica los artículos 5o., 12, y 20 de la Ley núm. 3726, sobre Procedimiento de Casación, ${ }^{18}$ al considerar que "la cuantía mínima, mejor conocida en doctrina como summa cassatio-

18 El acápite c), párrafo II, del artículo 5o. de la Ley núm. 491-08 establece que: "las sentencias que contengan condenaciones que no excedan la cuantía de doscientos (200) salarios mínimos del más alto establecido para el sector privado, vigente al momento en que se inter- 
nis, es de configuración legislativa, tal cosa también ha de permitir la optimización del recurso de casación, de tal suerte que no todos los casos lleguen a la Suprema Corte de Justicia, pero sí se precisa crear un sistema más equilibrado que permita que, con independencia de que exista un límite general que restrinja por su cuantía los asuntos que acceden a la Suprema Corte, se abra una vía alternativa con base en el interés casacional que autorice a dicho órgano judicial a conocer aquellos asuntos que por su trascendencia jurídica o por la ausencia de jurisprudencia constituyan una ocasión adecuada para la fijación de una concreta doctrina".

- La sentencia TC/0563/15 determinó que la disposición contenida en el artículo 44.1 del Código de Trabajo, para que sea conforme a la Constitución en su artículo 42.3, debe interpretarse en función de las excepciones al principio de la voluntariedad de los reconocimientos médicos, cuando sea imprescindible para evaluar los efectos de las condiciones de trabajo sobre la salud de los trabajadores, o para verificar si el estado de salud del trabajador puede constituir un peligro para él mismo, para los demás trabajadores o para otras personas relacionadas con la empresa.

\section{EFECTO TRANSFORMADOR DE LAS RELACIONES LABORALES} Y REFORMA LABORAL

Las decisiones del TC dominicano han propiciado en cierta medida la reconstrucción de la legislación laboral en República Dominicana, a través del carácter vinculante de las sentencias del TC. Cada vez que se establece un precedente en uno de los aspectos relacionados con el derecho fundamental al trabajo, debe ser observado tanto por los legisladores, aplicadores y destinatarios de estas normas.

Por otra parte, la jurisprudencia constitucional en materia laboral ha contribuido también al reconocimiento de prerrogativas laborales en beneficio de personas que originalmente no tenían una relación laboral directa, entre los clásicos sujetos del derecho del trabajo. Lo que ha favorecido a tomar en cuenta aspectos nuevos en las relaciones laborales clásicas.

ponga el recurso. Si no se ha fijado en la demanda el monto de ésta, pero existen elementos suficientes para determinarlo, se admitirá el recurso si excediese el monto antes señalado". 
En el gráfico 6, se muestra la evolución de sentencias emanadas del TC relacionadas con el aspecto laboral durante el periodo 2012-2015.

\section{GRÁFICO 6. SENTENCIAS CONSTITUCIONALES \\ EN MATERIA LABORAL}

(2012-2015)

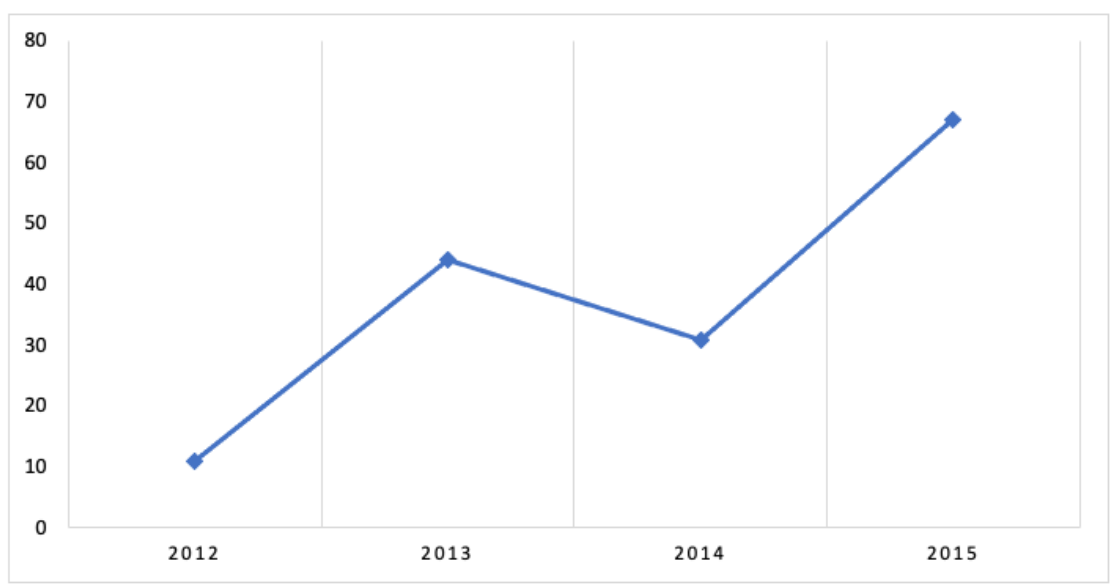

FUENTE: Elaboración propia.

El comportamiento de la actividad jurisdiccional muestra un ligero aumento en la tasa inicial de la jurisprudencia constitucional en materia laboral del TC, durante el periodo del análisis, pasando de un 10.57\% en 2012 a un $10.7 \%$ en 2015 . A la vez que se observa un patrón bianual en las decisiones emanadas del TC; esto es en los periodos 2012-2013 y 2014-2015.

En esa misma línea, este patrón de comportamiento en las sentencias dictadas por el TC en la garantía de los derechos laborales, contribuye a confirmar la capacidad que tienen las relaciones laborales para incidir en la actividad jurisdiccional del TC.

En el gráfico 7 se presenta el comportamiento de las relaciones laborales que formaron parte de la actividad jurisprudencial constitucional en materia laboral. Asimismo, muestra un aumento creciente de la protección constitucional del derecho fundamental al trabajo de los trabajadores públicos, por el TC. Asimismo, se vislumbra la disminución de los reclamos de empleados privados, aunque en este último caso se mantiene un comportamiento síncrono bianual de la jurisprudencia constitucional laboral, que aparece en el gráfico 6. 


\section{GRÁFICO 7. RELACIONES LABORALES Y ACTIVIDAD JURISPRUDENCIAL} CONSTITUCIONAL (2012-2015)

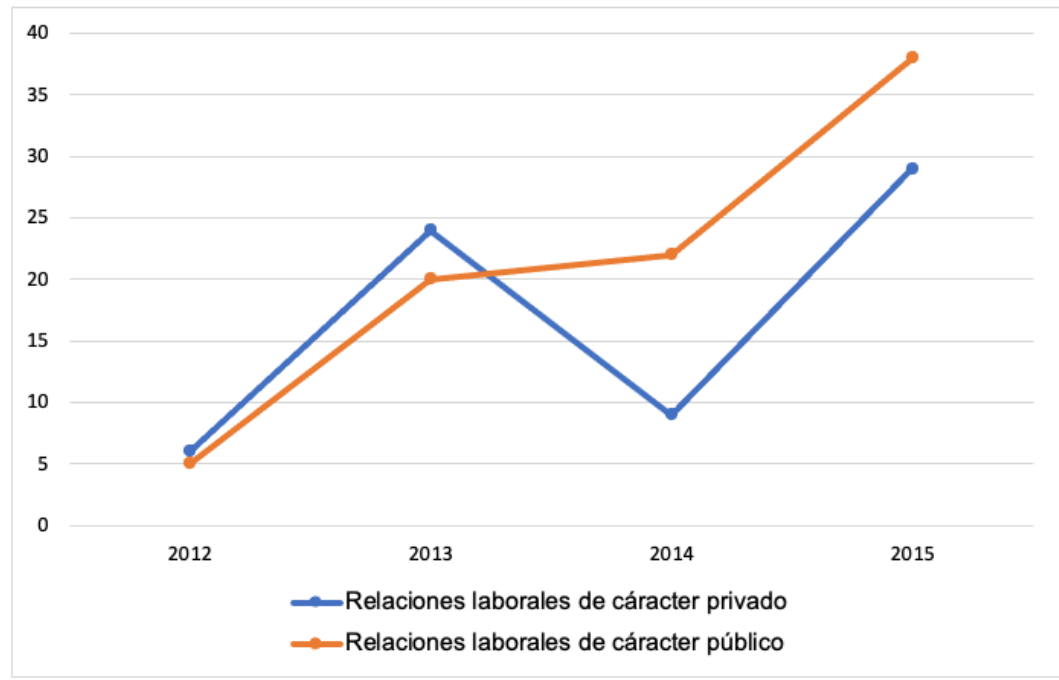

FUENTE: Elaboración propia.

La actividad de la jurisdicción laboral ha contribuido a la fluctuación de la cantidad de decisiones emanadas. En ese orden, esto se debe al marco jurídico que regula los aspectos laborales de los empleados públicos, la estructura de la jurisdicción contenciosa administrativa y la resolución de conflictos en sede administrativa; que explican el aumento del reclamo de los servidores públicos.

En otro orden, si se toma en cuenta el desarrollo de la tasa de desocupación elaborada por el Banco Central de República Dominicana durante el periodo de estudio 2012-2015, notaremos también que la actividad jurisdiccional en cuanto al derecho fundamental al trabajo a través de los indicadores elaborados se constituye en un indicador de los fenómenos sociojurídicos que se suscitan en el Estado dominicano.

En tal sentido, según el Banco Central de República Dominicana la tasa de desocupación ampliada ${ }^{19}$ para el año 2012 fue de un 14.7\%. En 2013, dicha tasa aumentó a un 15\%, momento en que la cantidad de sentencias consti-

19 La tasa de desocupación ampliada se refiere al porcentaje de la población desempleada respecto a la población económicamente activa. 
tucionales en materia laboral aumentaron, contribuyendo indirectamente al descenso de la cantidad de decisiones en el año 2014, cuando la tasa de desocupación igualmente disminuyó a un 14.5\%.

Ahora bien, dicha disminución de un porcentaje respecto al 2014, acompañado de una tasa de desocupación de $14 \%$ en 2015 , incidieron en el aumento cuantitativo de las decisiones dictadas por el TC en el último periodo de estudio.

Con la finalidad de analizar cualitativamente el impacto de estas sentencias, en el gráfico 8 , se muestra en detalle los contenidos específicos del derecho fundamental al trabajo que estuvieron presente es como la base fundamental de las decisiones constitucionales durante el periodo 2012-2015.

\section{GRÁFICO 8. SENTENCIAS DEL TRIBUNAL CONSTITUCIONAL EN MATERIA LABORAL (2012-2015)}

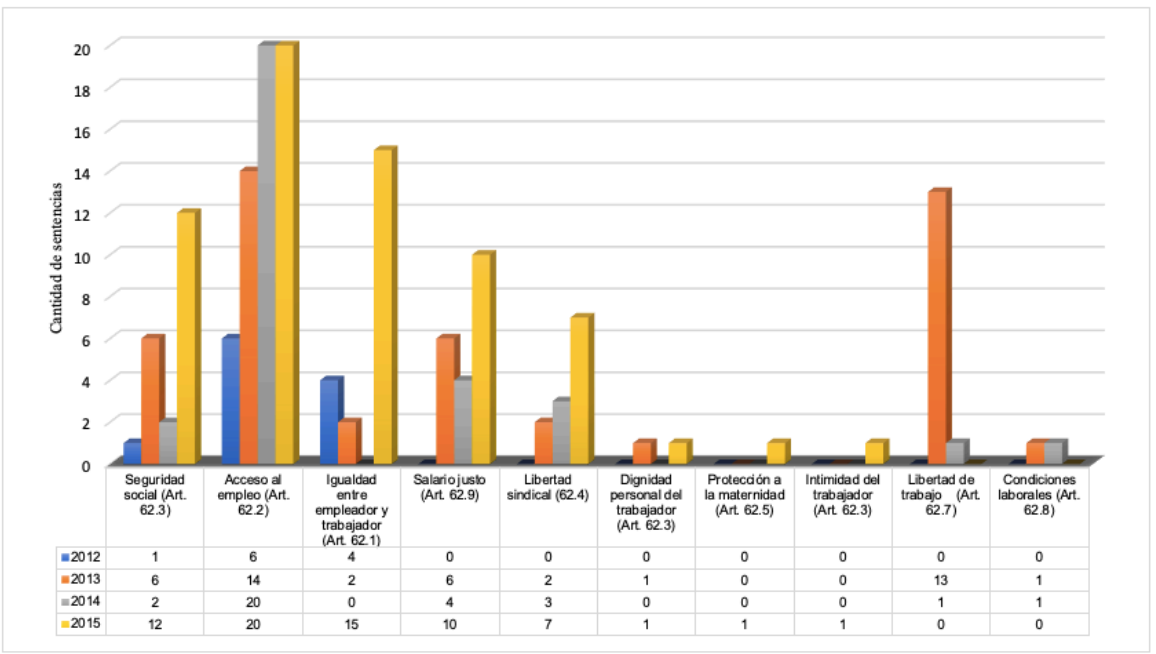

FUENTE: Elaboración propia.

El acceso al empleo, durante todo el periodo de análisis, prevaleció como el contenido específico de carácter fundamental laboral, más demandado ante el TC, seguido de la seguridad social (artículo 62.3 de la Constitución), la igualdad entre los empleadores y los trabajadores (artículo 62.1 de la Constitución), el salario justo (artículo 62.9) y la libertad sindical (62.4).

Lo anterior es interesante, en virtud de que los reclamos de acceso al empleo se corresponden con los servidores públicos (jueces, funcionarios, alcaldes, 
defensores públicos, militares, entre otros), que una vez desvinculados de sus puestos de trabajo, reclaman ante la jurisdicción constitucional la protección de su derecho fundamental al trabajo, procurando ser restituidos nuevamente.

En cuando a la seguridad social, es congruente con el desarrollo del Sistema Dominicano de Seguridad Social en el país, ya que cada vez más los ciudadanos requieren se les reconozca el derecho a una pensión justa, así como otras formas de protección social para ellos y sus familiares. Esto guarda estrecha relación con las acciones directas de inconstitucionalidad a las normas que conforman el marco jurídico de la seguridad social en República Dominicana.

En el gráfico 9, se aprecia de una forma más resumida lo presentado en el gráfico 8 , los derechos específicos de carácter laboral reclamados ante el TC.

\section{GrÁFICO 9. DERECHOS ESPECÍFICOS DE CÁRACTER LABORAL RECLAMADOS ANTE EL TC (2012-2015)}

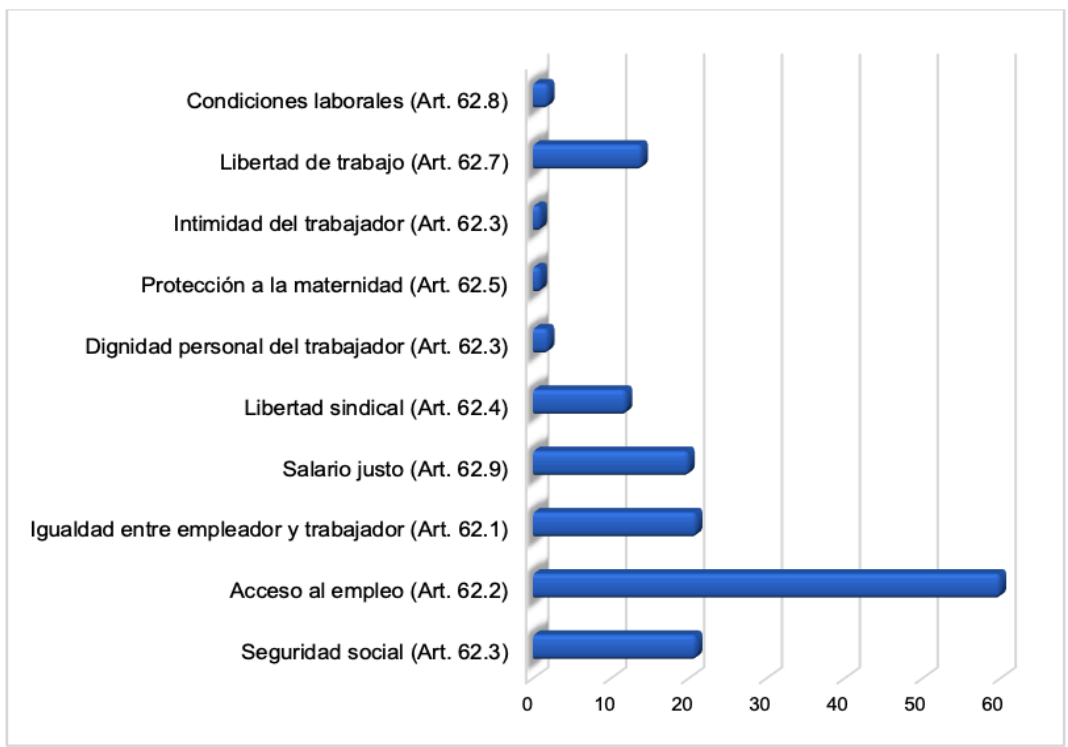

FUENTE: Elaboración propia.

En torno a la igualdad entre los empleadores y trabajadores, ésta tiene una gran demanda ante la jurisdicción constitucional, mayormente por los 
empleadores, quienes consideran que tanto los órganos jurisdiccionales y el marco jurídico laboral se inclinan a beneficiar al trabajador.

El reclamo del salario justo guarda relación con las demandas que persiguen el pago de las prestaciones laborales y derechos adquiridos, luego de terminada la relación laboral o en reparo de indemnizaciones. La libertad de trabajo se presenta en la forma de acciones que pretenden modificar las normas laborales. Por último, la libertad sindical, a través de los sujetos del derecho colectivo de trabajo (sindicatos), ha encontrado una nueva plataforma para obtener la protección de tan importante prerrogativa laboral.

\section{REFLEXIONES FINALES}

En el análisis exhaustivo, sistemático e integral de las interpretaciones constitucionales del derecho humano y fundamental al trabajo, durante el primer cuatrienio de actividad jurisdiccional del TC dominicano, se observa un desarrollo vertiginoso de la jurisprudencia constitucional en materia laboral en República Dominicana, que no constituye un fenómeno aislado respecto a lo que sucede en el contexto regional. Esto constituye un fenómeno que responde a una nueva corriente del constitucionalismo social, a través de la garantía de los derechos fundamentales de carácter laboral en la administración de justicia constitucional.

Los precedentes vinculantes de los tribunales y cortes constitucionales impactan positivamente la evolución de las normas jurídicas en material laboral, siempre en consonancia con el derecho humano y fundamental al trabajo consignado en la carta sustantiva. Al observar el incremento de las revisiones constitucionales de las decisiones jurisdiccionales en materia laboral, se percibe el empoderamiento de los ciudadanos — trabajadores - de un Estado.

En ese mismo orden, se advierte el valor axiológico y respeto de los principios constitucionales en la interpretación constitucional de las normas del ordenamiento laboral, en reparo y contraste con las tendencias liberales de flexibilización laboral que han seguido algunos países de América Latina, cuyos resultados no han sido tan favorables como se pronosticara.

De la mano con lo anterior, y en la opinión de varios doctrinarios, se ha originado la transición hacia una nueva etapa del constitucionalismo social —neoconstitucionalidad o neoconstitucionalismo- del derecho fundamental al trabajo en América Latina, impulsado por la jurisprudencia vinculante 
de los tribunales y cortes constitucionales. Esto es producto del carácter de los principios y valores contenidos en la carta sustantiva aplicables a las relaciones jurídicas en materia laboral.

Al hilo de estas consideraciones, resulta menester repensar el alcance y las garantías constitucionales al derecho humano y fundamental al trabajo, por el poder que tiene como efecto constitucionalizador en el ordenamiento laboral, más aún ante las discusiones de reformas a los corpus iuris laboral a nivel regional; y en el caso dominicano, desde el 2013, sin resultados palpables, pero sí latentes como demuestra este artículo.

La configuración actual del control de constitucionalidad con la participación del TC ha contribuido a asentar el constitucionalismo social en el Estado constitucional dominicano, específicamente tomando un rol más activo que la configuración previa — antes de la instauración y puesta en funcionamiento de una jurisdicción constitucional especializada-.

\section{BIBLIOGRAFÍA}

CARbonell, M., y Ferrer, E., Los derechos sociales y su justiciabilidad directa, México, Instituto de Investigaciones Jurídicas UNAM, 2014.

CARBUCCIA, M., Jurisprudencia constitucional en materia laboral de la Suprema Corte de Justicia, sentencias y comentarios, Santo Domingo, Poder Judicial, 2015.

Carmona, E., El Estado social de derecho en la Constitución, Madrid, Consejo Económico y Social, 2000.

CENTro de Estudios Constitucionales del TC de Perú, Jurisprudencia y doctrina constitucional laboral, Perú, Palestra Editores, 2006.

Constitución de la República Dominicana, Gaceta Oficial, núm. 10561, 26 de enero de 2010.

DeCreto núm. 286-13, Gaceta Oficial, núm. 10733, 2 de octubre de 2013.

FINJus, Constitución comentada por los jueces del Poder Judicial, 3a. ed., Santo Domingo, 2012.

FIX-ZAmudiO, H., et al., El constitucionalismo en las postrimerías del siglo XX, t. V: La Constitución mexicana, 70 años después, México, UNAM, 1988.

GARGARELLA, R., "El constitucionalismo latinoamericano y la 'sala de máquinas' de la Constitución (1980-2010)”, Gaceta Constitucional, Argentina, núm. 48.

GonzÁlez, P. y ARnaldo, E., Comentarios a la Constitución dominicana, Madrid, La Ley, 2012, 2 t. 
Hostos, E., Lecciones de derecho constitucional, Santo Domingo, Raymundo Amaro Guzmán, 1982.

Jorge, E., Derecho constitucional, Santo Domingo, Gaceta Judicial, 2003, vol. I.

Jorge, E., Derecho constitucional, Santo Domingo, Gaceta Judicial, 2012, vol II.

KURCZYN, P. et al., Relaciones laborales en el siglo XXI, México, UNAM-Instituto de Investigaciones Jurídicas, 2001.

LEY núm. 137-11, Orgánica del Tribunal Constitucional y de los Procedimientos Constitucionales, 13 de junio de 2011, Gaceta Oficial núm. 10622.

Mendieta y Núñez, L., Derecho Social, México, Porrúa, 1967.

Noguera, A., y NAVAS, M., Los nuevos derechos de participación en ecuador ¿derechos constituyentes o derechos constitucionales?, Valencia, Tirant lo Blanc, 2016.

PETIT, L., El Estado social: los contenidos mínimos constitucionales de los derechos sociales, Caracas, Jurídica Venezolana, 2015.

Quiroga, H., Derecho constitucional latinoamericano, México, UNAM-Instituto de Investigaciones Jurídicas, 1991.

RaY, M., Opinión Constitucional, Santo Domingo, Amigo del Hogar, 2014.

Rolla, G., Derechos fundamentales, estado democrático y justicia constitucional, México, UNAM, 2002.

SÁnCHEZ, R., La trascendencia del constitucionalismo social en América Latina (Caso México). Cuestiones Constitucionales, núm. 27, 2012, disponible en bttp:// wmw. scielo.org.mx/scielo.php, consultado el 15 de julio de 2018.

Suprema Corte de Justicia, 12 años de justicia constitucional en la República Dominicana, Santo Domingo, 2010.

Suprema Corte de Justicia, Los jueces de la Suprema Corte de Justicia comentando los derechos individuales y sociales, Santo Domingo, 2007.

ZAGReBelsky, G., "Constitucionalismo", Revista Derechos y Libertades, vol. II, núm. 29, 2013. 